Recebido em 07/2013. Aceito para publicação em 01/2014.

\title{
PERFIL CLÍNICO DAS MULHERES SUBMETIDAS AO EXAME PAPANICOLAU NA USF - BREJINHO NO ANO DE 2011
}

\section{CLINICAL PROFILE OF WOMEN SUBMITTED TO PAP SMEARS AT USF - BREJINHO IN 2011}

\author{
Valquíria Borges da Silva ${ }^{1}$ \\ Emilia Pricila Andrade dos Santos ${ }^{1}$ \\ Rivaldo Lira Filho
}

Resumo: O câncer de colo de útero é um importante problema de saúde pública, principalmente, em decorrência da crescente exposição a fatores de risco ambientais e da modificação de hábitos de vida da população. Com o objetivo de traçar o perfil clínico de mulheres submetidas ao exame Papanicolau, na USF-Brejinho, zona rural de um município do interior do Maranhão, no ano de 2011, foi realizado um estudo descritivo com resultados de exames papanicolau de 295 mulheres, por meio de um levantamento de dados, existentes em seus prontuários e livros de registro de enfermagem. De acordo com os resultados obtidos nesse trabalho, foram encontrados $2,1 \%$ de exames positivos para alterações celulares epiteliais escamosas e glandulares; destes, 0,6\% referentes a atipias de significado indeterminado em células escamosas, $1,5 \%$ a atipias de significado indeterminado em células glandulares e, 1,25\% com lesão intraepitelial cervical de baixo grau. Vale ressaltar que essas lesões, consideradas como precursoras do carcinoma de colo uterino, desempenham importante papel no processo de evolução para o câncer cervical. Isso demonstra a necessidade de um aporte às atividades de prevenção primária e de detecção precoce dessas lesões, na tentativa de minimizar as taxas de mortalidade atribuídas a essa patologia em nossa região.

Palavras-chave: câncer de colo do útero; exame Papanicolau; enfermagem.

\begin{abstract}
Cancer of the cervix is an important public health problem, mainly due to the increasing exposure to environmental risk factors and modification of people's life habits. To trace the clinical profile of women undergoing Pap smears at USF - Brejinho, a rural municipality in the state of Maranhão, in 2011, a descriptive study with Pap test results of 295 women was conducted, through a survey of data existing in patient records and nursing records. The results obtained in this study found $2.1 \%$ of positive tests for changes of squamous and glandular epithelial cells. Of these, $0.6 \%$ were related to atypical squamous cells of undetermined significance, $1.5 \%$ atypical glandular cells with undetermined significance, and $1.25 \%$ with low-grade cervical intraepithelial lesions. It is noteworthy that these lesions are considered precursors of cervical cancer, playing an important role in the evolution of cervical cancer. This demonstrates the need for primary prevention activities and early detection of these lesions in an attempt to minimize mortality rates attributed to this disease in this region.
\end{abstract}

Keywords: cervical cancer; pap smears; nursing.

\footnotetext{
1 Graduada em Enfermagem - Universidade Estadual do Maranhão - UEMA e Especialista em Saúde Pública e Saúde da Família - Faculdade Dom Bosco. E-mails: valquiriabs16@hotmail.com; emiliapricila@hotmail.com.

2 Graduado em Enfermagem - UFPI e Especialista em Obstetrícia e em Oncologia - UFPI. Discente da UEMA. E-mail: rivaldolirafilho@hotmail.com.
}

Revista Univap - revista.univap.br

São José dos Campos-SP-Brasil, v. 20, n. 35, jul.2014. ISSN 2237-1753 


\section{INTRODUÇÃO}

Em 2008, de um total de 58 milhões de mortes ocorridas no mundo, o câncer foi responsável por 7,6 milhões, o que representou $13 \%$ de todas as mortes. Dentre os tipos de cânceres existentes, o de colo de útero apresentou um número de 655 mil casos. Do total de óbitos por câncer em 2008, mais de 70\% ocorreram em países de média ou baixa renda. Estima-se que em 2020 o número de casos novos anuais seja da ordem de 15 milhões. Cerca de $60 \%$ desses novos casos ocorreram em países em desenvolvimento (INSTITUTO NACIONAL DE CÂNCER, 2008).

O colo do útero é revestido, de forma ordenada, por várias camadas de células epiteliais pavimentosas, que, ao sofrerem transformações intraepiteliais progressivas, podem evoluir para uma lesão cancerosa invasiva em um período de 10 a 20 anos (BRASIL, 2002).

Uma marcante característica do câncer do colo do útero é a sua consistente associação, em todas as regiões do mundo, com o baixo nível socioeconômico, ou seja, com os grupos que têm maior vulnerabilidade social. Segundo dados do INCA (2002), nesses grupos é que se concentram as maiores barreiras de acesso à rede de serviços para detecção e tratamento precoce da doença e de suas lesões precursoras, advindas de dificuldades econômicas e geográficas, insuficiência de serviços e questões culturais.

Prevenção, rastreamento e detecção são as melhores estratégias para debelar o câncer. Podemos dividir a prevenção em duas vertentes: a prevenção primária, em que são focadas medidas que garantam que o câncer não chegue a manifestar; e a prevenção secundária, com o objetivo de detectar e tratar o câncer precocemente, enquanto ainda se encontra em estágio possível de cura (CHAVES, 2010).

No Brasil, a estratégia de rastreamento recomendada pelo Ministério da Saúde (MS) é o exame citopatológico, ou exame papanicolau, prioritariamente em mulheres de 25 a 64 anos. O exame citopatológico do colo uterino é uma das armas mais eficazes para a prevenção do câncer, sendo, relativamente, de baixo custo. A eficácia desse tipo de rastreamento é melhor quanto menor o intervalo entre as coletas para citologia, demonstrada por uma redução da incidência cumulativa de câncer invasor para 95\% quando a coleta é realizada anualmente. É recomendado para todas as mulheres sexualmente ativas (INSTITUTO NACIONAL DE CÂNCER, 2011).

Tendo em vista a problemática do câncer de colo de útero para a saúde pública e a necessidade em elaborar estratégias para a melhoria da promoção de saúde, este estudo teve por objetivo: traçar o perfil clínico de mulheres submetidas à realização do exame papanicolau no ano de 2011, em um povoado da zona rural de um município do interior do Maranhão.

\section{METODOLOGIA}

Trata-se de uma pesquisa descritiva, do tipo documental, desenvolvida em uma Unidade de Saúde da Família-USF, em um povoado da zona rural de um município do interior do Maranhão. Os residentes desse povoado são considerados de classe socioeconômica baixa e média. Os sujeitos participantes da pesquisa foram mulheres submetidas à realização do exame Papanicolau, na USF, no ano de 2011, oriundas do povoado estudado e povoados adjacentes. 
Os critérios de inclusão foram: ser mulher, ter prontuário ou dados prescritos nos livros de registro da instituição, ter realizado o exame Papanicolau, no ano de 2011, na USF, e a instituição autorizar a realização da pesquisa pelo TCl - Termo de Consentimento da Instituição.

Previamente, foi solicitada à Coordenação da Atenção Básica do município, a autorização para a realização do estudo com os documentos dos sujeitos envolvidos, recebendo parecer favorável. Na realização deste estudo, foram observados os pressupostos da Resolução 196/96 do Conselho Nacional de Saúde/Ministério da Saúde - CNS/MS, que dispõe sobre pesquisas com seres humanos. O pré-projeto foi enviado ao Comitê de Ética e Pesquisa da Universidade Estadual do Maranhão para fins de apreciação, o qual obteve aprovação, com parecer № 262.533 .

A amostra foi constituída por 295 mulheres que realizaram o exame papanicolau na USF, no ano de 2011. O processo de coleta de dados se deu por meio de um levantamento realizado nos prontuários das mulheres assistidas pela USF e pelas anotações de enfermagem, nos livros de registros e anotações dos procedimentos de enfermagem. Foram coletadas as características socioeconômicas dessas mulheres, bem como de questões relacionadas ao tema.

\section{RESULTADOS}

O conteúdo referente ao instrumento proposto fora obtido por meio de um levantamento de dados (por um roteiro preparado pelos autores), aos quais foram coletados no prontuário das clientes e livros de registros da própria USF. Os dados sociodemográficos se distribuíram, quantitativamente, em tabela, englobando: idade, estado civil, escolaridade, tipo de trabalho e procedência, e os dados específicos distribuíram-se, quantitativamente, em duas tabelas, e em categorias pertinentes relacionadas ao assunto abordado, expressando o perfil clínico de mulheres submetidas ao exame papanicolau no ano de 2011.

Foram realizados, na USF, 338 exames papanicolau, sendo que 2 não tinham anotações dos possíveis resultados e 16 apontaram amostra insatisfatória, finalizando 320 exames papanicolau analisados, de 295 mulheres, pois 25 delas repetiram o exame no mesmo ano.

Em relação às características gerais das mulheres estudadas, observou-se (Tabela1), predominantemente, 128 (43,3\%) com faixa etária entre 29 a 44 anos de idade, 102 (34,5\%) eram casadas e 108 (36,6\%) não apresentavam registros de estado civil. Quanto à escolaridade, 116 $(39,3 \%)$ eram alfabetizadas e $93(31,5 \%)$ não apresentavam informações referentes, $131(44,4 \%)$ eram do lar e $166(56,2 \%)$ procediam de povoados adjacentes. 
Tabela 1 - Caracterização das participantes do estudo - Dados demográficos

\begin{tabular}{|c|c|c|}
\hline ldade & $f$ & $\%$ \\
\hline $13-28$ & 116 & 39,3 \\
\hline $29-44$ & 128 & 43,3 \\
\hline $45-60$ & 39 & 13,2 \\
\hline$>60$ & 12 & 4,2 \\
\hline Estado civil & $f$ & $\%$ \\
\hline Solteira & 70 & 23,7 \\
\hline Casada & 102 & 34,5 \\
\hline Viúva & 15 & 5,2 \\
\hline Não informado & 108 & 36,6 \\
\hline Escolaridade & $f$ & $\%$ \\
\hline Não alfabetizado & 86 & 29,2 \\
\hline Alfabetizado & 116 & 39,3 \\
\hline Não informado & 93 & 31,5 \\
\hline Tipo de trabalho & $f$ & $\%$ \\
\hline Do lar & 131 & 44,4 \\
\hline Fora do lar & 52 & 17,6 \\
\hline Lavradora & 69 & 23,5 \\
\hline Outros & 43 & 14,5 \\
\hline Procedência & $f$ & $\%$ \\
\hline Brejinho & 126 & 42,7 \\
\hline Adjacências & 166 & 56,2 \\
\hline Sem informação & 3 & 1,1 \\
\hline
\end{tabular}

Fonte: USF - Dr. José de Assunção Brandão, Caxias/MA.

Quanto às alterações celulares benignas, 159 (49,7\%) das amostras estavam dentro dos limites de anormalidade, sendo o maior destaque para inflamação com 19,5\% dos casos e atrofia com inflamação com 1,9\% e metaplasia escamosa imatura com $0,6 \%$ dos casos. Quanto à análise microbiológica dos exames citopatológicos, foi observado que a colonização cérvico-vaginal se deu, principalmente, por Gardnerella Vaginalis, $13 \%$, seguido de Candida sp com $8,4 \%$ e Cocos com $3,75 \%$ (Tabela 2). 
Tabela 2 - Distribuição da microbiologia dos resultados de exames papanicolau da Unidade de Saúde da Família-Brejinho, no ano de 2011

\begin{tabular}{lrr}
\hline \multicolumn{1}{c}{ Microbiologia } & \multicolumn{1}{c}{$\boldsymbol{F}$} & \multicolumn{1}{c}{$\%$} \\
\hline Cocos & 12 & 3,75 \\
Bacilos & 1 & 0,3 \\
Lactobacilos sp & 3 & 0,9 \\
Candida sp & 27 & 8,4 \\
Gardnerella & 42 & 13,1 \\
Gardnerella/ Mobiluncus & 17 & 5,31 \\
Trichomonas & 7 & 2,2 \\
\hline
\end{tabular}

Fonte: USF - Dr.José de Assunção Brandão, Caxias/MA.

Conforme os resultados obtidos das amostras, foram encontradas $2,1 \%$ de alterações celulares escamosas e glandulares (Tabela 3 ), 12 casos $(3,75 \%)$ de células atípicas de origem indefinida não-neoplásica, e 4 casos $(1,25 \%)$ de lesão intraepitelial de baixo grau.

Tabela 3 - Distribuição de alterações celulares dos resultados de exames papanicolau da Unidade de Saúde da Família-Brejinho, no ano de 2011, por faixa etária

\begin{tabular}{lrr}
\hline \multicolumn{1}{c}{ Alterações celulares } & $\boldsymbol{F}$ & $\%$ \\
\hline Células escamosas atípicas de significado indeterminado não-neoplásicas & 2 & 0,6 \\
Células glandulares atípicas de significado indeterminado não-neoplásicas & 2 & 0,6 \\
Células glandulares atípicas de significado indeterminado que não se pode excluir lesão & 3 & 0,9 \\
intraepitelial & 12 & 3,75 \\
Células atípicas de origem indefinida não-neoplásica & 4 & 1,25 \\
Lesão intraepitelial de baixo grau & \\
\hline
\end{tabular}

\section{Fonte: USF - Dr. José de Assunção Brandão, Caxias/MA.}

\section{DISCUSSÃO}

Este estudo foi baseado em uma análise de dados para avaliar o perfil clínico das mulheres submetidas ao exame Papanicolau, no ano de 2011, na USF de um povoado da zona rural de um município do interior do Maranhão.

As pacientes que procuraram atendimento no serviço prestado são relativamente adultas (29 - 44 anos) e casadas. Como no estudo de Chaves (2010), isso nos faz refletir que há uma significativa melhora na aceitação das mulheres ao exame, pois o MS prioriza a faixa etária para a realização do exame de 25 a 60 anos de idade.

De acordo com a literatura, essa população se encontra numa faixa na qual, a incidência do Câncer ( $\mathrm{CA})$ de colo de útero é alarmante, visto que essa neoplasia pode ocorrer em mulheres jovens que iniciam a atividade sexual na adolescência e trocam constantemente, de parceiros, uma 
vez que sua incidência maior seja entre os 35 e 49 anos de idade (SANTOS, 2010).

Outro ponto a destacar é o baixo nível intelectual presente na maioria da amostra, o que aponta para a maior vulnerabilidade social. É nesse grupo que se concentram as maiores barreiras de acesso à rede de serviços para detecção e tratamento precoce da doença e de suas lesões precursoras, advindas de dificuldades econômicas e geográficas, insuficiência de serviços e questões culturais (INSTITUTO NACIONAL DE CÂNCER, 2002).

É importante, também, identificar as ocupações das mulheres, visto que há uma relação muito íntima com o nível de escolaridade, e da amostra 131 (41,9\%) desenvolvem suas atividades diárias no âmbito familiar, cuidando dos afazeres domésticos. Ocupações que implicam uma baixa renda são suscetíveis ao acometimento do CA de colo de útero (LOPES, 1995).

O nível socioeconômico e cultural, influência de forma direta na detecção precoce dessa doença, fazendo com que as mulheres de baixo nível de escolaridade e baixa renda familiar, adoeçam mais (ALPOROVITCH; ALPOROVITCH, 1992).

Das 320 citologias coletadas, verificam-se, microbiologicamente, uma predominância de casos de Gardnerella. De acordo com um estudo realizado por Oliveira et al. (2007) os dados verificados sugerem que a faixa etária e o tipo de ocupação da população feminina estudada são fatores que podem estar diretamente ligados a fatores que predispõem quadros de infecção por $\mathrm{G}$. vaginalis, em associação ou não com o Mobiluncus $\mathrm{sp}$, seja por condições associadas aos hábitos sexuais da população estudada, ou pela falta de boas práticas de higiene (dados não estudados), que acabam por provocar distúrbios da microflora vaginal.

Outro fator importante analisado nos resultados dos exames citopatológicos foram, 7 casos de lesões escamosas ou glandulares cervicais, o que confere a frequência de 2,1\%. Já, a lesão intrepitelial de baixo grau (LSIL) apresentou frequência de 1,25\%, que, de acordo com Gonçalves et al. (2010), nesse caso, a evolução para câncer cervical é incomum; no entanto, pode acontecer devido à progressão da lesão ao longo do tempo ou subdiagnóstico da citopatologia.

Cumpre ressaltar que essas lesões, consideradas como precursoras do carcinoma de colo uterino, desempenham importante papel no processo de evolução para o câncer cervical. Isso demonstra a necessidade de um aporte às atividades de prevenção primária e de detecção precoce dessas lesões, na tentativa de minimizar as taxas de mortalidade atribuídas a essa patologia. As ações voltadas para o diagnóstico precoce das lesões pré-malignas são de fundamental importância para a resposta terapêutica.

Para o Ministério da Saúde, a atuação do enfermeiro na prevenção do câncer tem sido objeto de estudo em diversos países e, cada vez mais, fica comprovada a importância desse profissional nos programas de educação em saúde (BRASIL, 1997).

\section{CONCLUSÃO}

O estudo descritivo documental realizado com os dados das mulheres submetidas ao exame Papanicolau, no ano de 2011, na USF da zona rural de um município do interior do Maranhão, na buscar de traçar o perfil clínico destas, levou às seguintes proposições: 
Há um predomínio de mulheres com faixa etária de 29 a 44 anos de idade. Em sua maioria casadas, ou união conjugal estável, com baixo nível de escolaridade e a ocupação principal é realizada dentro do âmbito familiar.

$\mathrm{Na}$ análise microbiológica, encontrou-se, com mais frequência, Gardnerella e, dentre as alterações celulares benignas, recebeu maior destaque os casos de inflamação, seguido por, atrofia com inflamação. Já, nas alterações celulares pré-malignas ou malignas, houve $2,1 \%$ de lesões escamosas ou glandulares.

Conhecer o perfil clínico de mulheres que realizaram o exame papanicolau em um determinado ambiente é de grande importância, pois possibilita a elaboração de políticas públicas voltadas à realidade desse local. Nesse contexto, nosso objetivo tornou-se válido, uma vez que o estudo possibilitou o reconhecimento de dados que poderão serem utilizados, para uma melhor organização de programas de prevenção, priorizando as necessidades voltadas a essa região.

\section{REFERÊNCIAS}

ALPOROVITCH, D.; ALPOROVITCH, S.K. Diagnóstico e prevenção do câncer na mulher. São Paulo: Santos; 1992.

BRASIL. Ministério da Saúde. Secretaria de Políticas de Saúde. Área Técnica de Saúde da Mulher. Assistência em Planejamento Familiar: Manual Técnico. 4. ed. Brasília: Ministério da Saúde, 2002. $152 \mathrm{p}$.

- Ministério da Saúde. Secretaria Nacional de Assistência à Saúde. Ações de Enfermagem para o controle de câncer. Rio de Janeiro: Pró-Onco, 1997. 59p.

CHAVES, A. C. M.; POPPE, M. C. M. Perfil de mulheres submetidas ao exame papanicolau na Unidade Básica de Saúde Moro da Liberdade-Manaus/AM- contribuições da enfermagem para a promoção da saúde. Monografia (Especialização em Saúde da Família) - Universidade Cândido Mendes. Florianópolis, 2010.

GONÇALVES, Z. R. et al. Lesões escamosas intraepiteliais de baixo grau: conduta em mulheres adultas. Revista Feminina, v. 38, n. 7, pp. 32-45, jul, 2010. Disponível em: <files.bvs.br/upload/S/0100-7254/2010/v38n7/a1517.pdf>. Acesso em: 19 maio 2013.

INSTITUTO NACIONAL DO CÂNCER. Ministério da Saúde. Incidência de Câncer no Brasil Estimativa 2008. Rio de Janeiro: Inca, 2008. Disponível em: <http://saudedofuturo.wordpress.com/2008/01/04/incidencia-de-cancer-no-brasil-estimativa-2008inca>. Acesso em: 31 maio 2013. - José Alencar Gomes da Silva. Coordenação Geral de Ações Estratégicas. Coordenação de Prevenção e Vigilância. Estimativa 2012: incidência de câncer no Brasil. Rio de Janeiro: INCA, 2011.

Coordenação de Prevenção e Vigilância (Conprev). Falando sobre câncer do colo do útero. Rio de Janeiro: MS; INCA, 2002. 59p. 
LOPES, C.; CORRÊA, M. E. G. Acompanhamento a saúde da mulher. Brasília: Ministério da Saúde, 1995. 300p.

OLIVEIRA, A. B. et al. Prevalência de Gardnerella e Mobiluncus em exames de colpocitologia em Tome-Açu, Pará. Revista Paraense de Medicina, v. 21, n. 4, pp. 47-51, dez. 2007.

SANTOS, M. S.; MACÊDO, A. P. N.; LEITE, M. A. G. Percepção de usuárias de uma unidade de saúde da família acerca da prevenção do câncer do colo do útero. Rev. APS, Juiz de Fora, v. 13, n. 3, pp. 310-319, 2010. 